\title{
Jazz and the 'Art' of Medicine: Improvisation in the Medical Encounter
}

\section{Paul Haidet, MD, MPH}

The Houston Center for Quality of Care and Utilization Studies, and Baylor College of Medicine, Houston, Tex

AC Annals Journal Club selection; see inside back cover or http://www. annfammed.org/AJCl.

Conflicts of interest: none reported

\section{CORRESPONDING AUTHOR}

Paul Haidet, MD, MPH

Houston Center for Quality of Care and Utilization Studies

VA Medical Center

2002 Holcombe Blvd (152)

Houston, TX 77030

phaidet@bcm.tmc.edu

\begin{abstract}
Improvisation is an important aspect of patient-physician communication. It is also a defining feature of jazz music performance. This essay uses examples from jazz to illustrate principles of improvisation that relate to an individual communication act (ie, building space into one's communication), a physician's communicative style (ie, developing one's voice), and the communicative process of the medical encounter (ie, achieving ensemble). At all 3 levels, the traditions of jazz improvisation can inform efforts to research and teach medical interviewing by fostering a contextualized view of patient-physician communication.
\end{abstract}

Ann Fam Med 2007;5:164-169. DOI: 10.1370/afm.624.

\section{INTRO}

The thing that sets Roy apart from other musicians is that be listens so well. He teaches you to listen carefully and to respond accordingly, to put things in perspective, not to simply go out for yourself.

Pianist McCoy Tyner, describing drummer Roy Haynes ${ }^{1}$

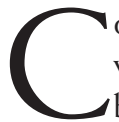
ommunication is central to human experience. It provides the vehicle through which we share ideas, coordinate actions, and build social structures. ${ }^{2}$ In medicine, important care processes such as information sharing and decision making occur in the context of patient-physician communication. ${ }^{3}$ A large and growing body of research shows that high-quality communication results in fewer medical errors, lower rates of litigation, and a variety of favorable social, psychological, and biological outcomes. ${ }^{4-12}$

Improvisation is an important aspect of patient-physician communication. The medical encounter, like most encounters involving communication, is typically unscripted and constructed "in the moment."13 Although physicians often follow biomedical patterns of inquiry, ${ }_{1}^{14}$ a patient-centered care ideal calls for adjustments to and departures from these patterns in response to concerns and perspectives voiced by the patient. ${ }^{15}$ In other words, physicians often need to improvise when they encounter patients' unique illness narratives ${ }^{16}$ Improvisation guides a physician's process of making moment-to-moment communicative decisions (eg, what to say next, how to structure particular questions, which threads to follow, when to interrupt and when to let the patient keep going). Stephen Nachmanovitch, $\mathrm{PhD}$, a violinist and scholar on creativity and the spiritual underpinnings of art, described a tension between biomedical training and patients' novel contexts as he discussed the importance of improvisation in medicine:

"In real medicine you view the person as unique-in a sense you drop your training. You are immersed in the case itself, letting your view of it develop in context. You certainly use your training; you refer to it, understand it, ground yourself in it, but you don't allow your training to blind 
you to the actual person who is sitting in front of you. In this way, you pass beyond competence to presence. To do anything artistically, you have to acquire technique, but you create through your technique and not with it."17

As a communication educator and researcher, former disc jockey, and amateur jazz historian, I often marvel at the many parallels between jazz and medicine. For example, understanding jazz history can also enhance one's understanding of many modern medical issues. These issues include racial disparities, as experienced by cornetists Louis Armstrong and Bix Beiderbecke; the life-world of addiction, as embodied by saxophonist Charlie Parker; and leadership skills, as practiced by bandleaders such as Duke Ellington, Art Blakey, and others. Several scholars have used jazz to describe insights about organizational development ${ }^{18,19}$ and the practice of evidence-based medicine. ${ }^{13}$

Although many characteristics of jazz have analogies in medicine, jazz's central focus on improvisation is particularly relevant to patient-physician communication. Improvisation is the primary vehicle that jazz players use to relate and communicate musically with one another. ${ }^{20}$ When describing the improvisational process, many jazz musicians and critics use verbal communication metaphors. ${ }^{21}$ For example, jazz musicians will commonly describe a particular performance using phrases such as, "I said this, and then he said that, etc." In this essay, I turn the metaphor around and use jazz improvisation as a lens to explore patient-physician communication. Although such an exploration could take many directions, I focus on communication at 3 levels: (1) as an act, (2) as a trait, and (3) as an event. For each level, I begin with a description of jazz improvisation and follow with an exploration of the meaning that the description holds for patient-physician communication. Along the way, I suggest particular jazz performances to augment the essay. Listening to the performances, although not critical, will enhance the reading experience by providing an additional illustration of the concepts discussed. Links to obtain the performances can be found in the Supplemental Appendix, which is available online-only at http://www.annfammed. im org/cgi/content/full/5/2/164/DC1.

\section{A COMMUNICATIVE ACT: CREATING SPACE}

Man, you don't bave to play a whole lot of notes. You just bave to play the pretty ones.

Trumpeter Miles Davis 22

During the medical encounter, physicians engage in a number of communicative acts, including question asking, information giving, and supportive talk. ${ }^{23}$ Researchers and educators have devised elaborate coding schemes to characterize the content and process of such acts. ${ }^{24-27}$ In my experience as a practitioner and teacher, I have found the act of providing communicative space to the patient to be one of the most powerful yet underused skills by physicians. ${ }^{28}$

What is space and how does it relate to jazz or patient-physician communication? When I am in the room with a patient, I sometimes think about how Miles Davis improvised. Miles came of age during the bebop era of jazz, when dominant trumpet players such as Dizzy Gillespie and Fats Navarro played blistering solos in the upper register at breakneck speed. It was said that Miles lacked the technical skill to play like Dizzy or Fats; however, whatever technical ability Miles did or did not have, his brilliance as an improviser manifested itself not so much in what he played as in what he did not play. To hear a solo by Miles is to hear space. Miles does not play a lot of notes, he just plays the right ones. He conserves notes, plays them at a relaxed pace, plays on the "back end" of the beat, and drops musical hints that allow the listener to use their imagination to fill in the phrases. The effect in songs such as "All Blues" (Columbia/Legacy CD Kind of Blue, CK64935) is that it becomes easy to hear not only the solo, but also what the rest of the band is playing. The solo voice gently leads one to hear the sum total of the music_-not just the soloist's musical statements way out in front, but those statements within the broader context of the whole band. ${ }^{29}$

As a physician, I strive to use communicative space as Miles did. Rather than take up all the space in the conversation with strings of "yes/no" questions or long physiological explanations, I find that I am at my best when I can give patients space to say what they want to say, using my communications to gently lead patients through a telling of the illness narrative from their perspective, rather than forcing the narrative to follow my biomedical perspective. ${ }^{30}$ In this space, patients often either tell their story, allowing me to understand the context around their symptoms, or ask the questions that allow me to tailor my explanations to their unique concerns. Unfortunately, in our culture, we are not generally comfortable with pauses or quiet. When the situation is compounded by the chaos of a busy clinic, it becomes difficult to remain focused and open to the directions that patients take us. For most practitioners, space does not come naturally; it takes practice and discipline to develop. ${ }^{31}$

Because space is multidimensional, it is a complex concept to research or teach. It requires attention to both communicative and narrative parameters. Communicative parameters include not only silence (as measured by metrics such as total physician and patient talk time), but also latency (the time between 
the end of the patient's statements and the beginning of the physician's statements) and pace (the number of words one utters per minute). Narrative parameters include care in the application of redirections (eg, interruptions, changes in the subject) and specific attention to communicative constraints placed on the patient (eg, the yes/no constraint inherent in closedended questions). When practitioners effectively use space, paying attention to both communicative and narrative parameters in the conversation, patients do not feel pressured or forced to omit information from their story. ${ }^{32}$ Rather, they are freed up to describe their health concerns on their own terms. ${ }^{33-35}$

\section{A COMMUNICATIVE TRAIT: DEVELOPING VOICE}

After the jazzman bas learned the fundamentals of bis instrument and the traditional techniques of jazz ... be must then "find bimself," must be reborn, must find, as it were, bis soul. He must achieve, in short, bis self-determined identity.

Ralph Ellison ${ }^{36}$

An important task for young jazz improvisers is to develop their voice. Learning musical theory, gaining familiarity with jazz scales and chord structures, mastering an instrument, apprenticing in the real world, and learning the repertoire of common songs are all important milestones; however, these alone are not enough to achieve musical success. Although the knowledge and skills are essential, the jazz musicians who eventually achieve critical and historical impact are those who channel the theory, technique, and ideas of their predecessors through their own personalities, feelings, and experiences. In this way, they develop a sound that is fresh and original in a process often called developing one's voice. This process requires curiosity, self-reflection, a clear and frequently revisited sense of purpose, and attention to the musical contexts that young musicians find themselves in. ${ }^{37,38}$

An excellent example of the development of improvisational voice is the evolution of saxophonist John Coltrane's playing in the 1950s and 1960s. Through his interactions with mentors such as trumpeter Miles Davis, pianist Thelonious Monk, and others, Coltrane's improvisations went from unexciting interpretations of his era's predominant musical forms to explosive flurries of patterns at speeds so great that the notes seemed to blur together, an effect that fellow musicians and critics came to call sheets of sound. Those sheets of sound were a hallmark of Coltrane's unique voice and can be heard on a number of recordings including "Giant Steps," which was recorded in 1959 (Atlantic Records CD Giant Steps, 1311-2). Although earlier recordings reveal that Coltrane possessed the technical skill to play sheets of sound as early as 1956, his fully mature voice, with its unique phrasings and idiosyncrasies, did not become evident until years later. During that time, Coltrane was undergoing an intense exploration of his life, his goals, his music, and his spirituality. This exploration translated musically into the development of his unique voice. ${ }^{39}$

Like jazz musicians, physicians need to develop their improvisational voice. Basic communication skills, such as agenda setting, effective use of open- and closed-ended questions, and patient-centered interviewing techniques, remain the building blocks of good communication ${ }^{40}$; these skills are like the scales that a musician must master. Similarly, the common communicative scenarios, such as breaking bad news, counseling for behavior change, and conversing about end-of-life issues, are like the songs that a musician must learn. ${ }^{41}$ Learning does not end at the basic skills or patterns of communication, however. Physicians must begin to incorporate knowledge and skills into their own personal style. They must creatively apply this style in each encounter in a way that fits well with the particular context and the communications of the patient. As an example, consider the bad news scenario. Experienced patient-centered doctors do not all break bad news in the same manner, ${ }^{42}$ nor do they all rigidly follow generally accepted guidelines ${ }^{43,44}$ for breaking bad news. Although there might be points of commonality, patient-centered physicians will do and say things in a manner that honors not only the humanity of the patient, but their own humanity as well. In a sense, these physicians "show up" in the medical encounter, rather than adopting a third-party stance that can act as a barrier to relationship building. Educators and researchers are beginning to realize that a communicative process that honors both patient and physician will strengthen the relationship that develops. ${ }^{45}$ Skill, technique, and theory provide a foundation, or point of departure, for a physician to develop his or her voice and bring it to the medical encounter.

\section{A COMMUNICATIVE EVENT: CULTIVATING ENSEMBLE}

Group improvisation is a further challenge. Aside from the weighty technical problem of collective coberent thinking, there is the very buman, even social need for sympatby from all members to bend for the common result.

Pianist Bill Evans ${ }^{46}$

Voice is only the beginning, because it takes more than one voice to have a conversation. On the one hand, there is the voice of the soloist. On the other hand, there are the voices of the other band members, who, 
in great jazz performances, are improvising also. The tension for all players is how much space to take in the music and what to play in that space to support each other's musical statements. If the soloist and other players are not listening to each other, the music sounds disjointed and dissonant, as if they are playing past each other. The early 1960s trio of bandleader-pianist Bill Evans, bassist Scott LaFaro, and drummer Paul Motian showed the jazz world how an ensemble could all simultaneously solo and support each other. Evans and LaFaro in particular had developed such a level of mutual respect and empathic listening that there are points during recordings such as "Waltz for Debby" (Riverside CD Waltz for Debby, OJCCD-210-2) when it is difficult to discern whose is the solo voice and whose is the supporting one. LaFaro's bass and Evans' piano epitomized the concept of ensemble by building coherent and harmonious improvisational performances out of 2 individual instruments' statements. ${ }^{47}$

Communication Accommodation Theory (CAT) provides a verbal analogy for ensemble. In CAT, one's statements are viewed in the context of their partner's statements. This contextual view allows one's statements to be classified as either converging to or diverging from the partner's statements. For example, in response to a question, providing an answer that is topically appropriate would be seen as an act of convergence. On the other hand, asking an unrelated question in response to a question (eg, a doctor asking, "Are you short of breath?" in response to a patient's question, "Is my chest pain serious, doctor?") is an act of divergence. ${ }^{48}$ Acts of convergence and divergence influence the patient-physician relationship, because converging statements signify a desire to gain approval, affiliate, establish rapport, and communicate meaning effectively, whereas diverging statements aim to separate, exert control, and generally downplay the statements of the partner.

Physicians and patients can achieve ensemble in their improvisation by accommodating, where possible, to each others' statements and styles of communication. Although our prevailing culture generally positions the physician as the leader of the conversation, ideally, the medical encounter would be characterized by voices that exist in harmony, rather than one striving to dominate the other. ${ }^{49,50}$ A collective ensemble improvisation is therefore characterized by the physician's, patient's, and sometimes other voices making assertions, listening to what others have to say, supporting each other, and incorporating each others' ideas into a common understanding. ${ }^{30,34}$ This backand-forth communication is critical for the physician's understanding of the patient's illness perspective and for the patient's understanding of the biomedical pro- cesses underlying the illness and the therapies that medicine has to offer. ${ }^{51}$ Ensemble improvisation is the process that makes shared decision making possible, because it allows all voices to find common ground about the decisions to be made. ${ }^{52}$

What does it take for physicians to enter into ensemble with patients? As implied by the previous quotes from McCoy Tyner and Bill Evans, it takes recognition that all voices in the medical encounter have things to say that are as important as one's own statements. It takes listening aligned toward understanding, not just the collection of factual data. And it takes raising one's awareness to clues-nonverbal signals, fleeting glimpses of emotion, and key words (such as worried, concerned, and afraid)_and following up on these clues when they present themselves. ${ }^{53,54}$ The essence of ensemble, whether in jazz or in medicine, lies in looking beyond one's own perspective to see, understand, and respond to the perspectives of others.

\section{CODA}

The improvisational concepts of space, voice, and ensemble all go beyond a prevailing understanding of communication as verbal information exchange, and they foster a more holistic and contextualized view of communicative phenomena. ${ }^{55}$ For example, the concept of improvisational voice provides a bridge between basic communication skills training and the complexity of communication in real-world settings, because it provides a conceptual frame for viewing the integrated performance of multiple communication skills and patterns. Voice suggests that, beyond developing and demonstrating proficiency in individual skills, learners must also begin to develop their own personal style in applying those skills. This process raises some important questions for future work: How can one assess the progress of learners' development of their own unique voice? Does the development of voice occur in discrete stages or along a continuum? What kinds of activities (eg, reflection, observation with feedback) or combinations of activities foster physicians' development of voice? In what ways might the traditions of jazz education be applied in medical communication skills training? How does the development of voice relate to patient-centered outcomes, such as trust, participation, and satisfaction? If physicians bring their unique voice to the medical encounter, how would that relate to physician satisfaction and the prevention of burnout? In a similar fashion, the jazz concepts of space and ensemble may also lead to new directions for education and research.

In today's world of evidence and guidelines, physicians are at risk for reducing patients' complex diagnoses 
to simple algorithms that do not take into account critical contextual information. ${ }^{13}$ This risk exists as well for patient-physician communication. Physicians who focus on only a fixed set of questions or follow the same sequence of inquiry for every patient will miss opportunities to hear the patient's perspective, build partnerships, and bring their own selves to the work of patient care. Physicians must be skilled improvisers, able to efficiently explore the unique aspects of a patient's illness and communicate in a way that is in harmony with that patient's style, all while managing the tension between new territory and the established patterns inherent in their communicative and clinical training. As educators and researchers, we can draw on the traditions and knowledge of jazz musicians as we try to enhance the quality of improvisation in the medical encounter.

The real power and innovation of jazz is that a group of people can come together and create art_-improvised art_-and can negotiate their agendas with each other. And that negotiation is the art.

Trumpeter Wynton Marsalis ${ }^{20}$

To read or post commentaries in response to this article, see it online at http://www.annfammed.org/cgi/content/full/5/2/164.

Key words: Physician-patient relations; primary health care; patientcentered care; education, medical; humanities; music; communication; curriculum; theoretical models; behavioral medicine; health care delivery; health services research

Submitted July 28, 2005; submitted, revised, May 1, 2006; accepted May 28, 2006.

Ideas contained in this essay were presented in part as the keynote address at the American College of Physicians Southern California Regional Meeting, March 1, 2003, Los Angeles, Calif.

Funding support: This work was supported in part by the Relationship-Centered Care Research Initiative, an initiative of the Fetzer Institute, Kalamazoo, Mich.

Disclaimer: The opinions contained herein are those of the author and do not necessarily represent the views of the US Department of Veterans Affairs, Baylor College of Medicine, the Fetzer Institute, or the American College of Physicians.

Acknowledgments: Dr Haidet would like to acknowledge Barbara F. Sharf, PhD, and Tracy M. Volz, PhD, for helpful comments on early versions of this manuscript.

\section{References}

1. Stephenson S. Jazzed about Roy Haynes. Smithsonian. 2003;34: 107-114.

2. McCroskey J, Richmond V. Fundamentals of Human Communication: An Interpersonal Perspective. Long Grove, Ill: Waveland Press; 1995.

3. Simpson M, Buckman R, Stewart M, et al. Doctor-patient communication: the Toronto consensus statement. BMJ. 1991;303(6814): 1385-1387.
4. Kohn L, Corrigan J, Donaldson M, eds. To Err Is Human: Building a Safer Health System. Washington, DC: National Academy Press; 2000.

5. Kaplan SH, Greenfield S, Ware JE Jr. Assessing the effects of physician-patient interactions on the outcomes of chronic disease. Med Care. 1989;27(Suppl 3):S110-S127.

6. Greenfield S, Kaplan S, Ware JE Jr. Expanding patient involvement in care. Effects on patient outcomes. Ann Intern Med. 1985;102(4): 520-528.

7. Predictors of outcome in headache patients presenting to family physicians-a one year prospective study. The Headache Study Group of The University of Western Ontario. Headache. 1986;26(6):285-294

8. Deyo RA, Diehl AK. Patient satisfaction with medical care for lowback pain. Spine. 1986;11(1):28-30.

9. Bartlett EE, Grayson M, Barker R, et al. The effects of physician communications skills on patient satisfaction; recall, and adherence. J Chronic Dis. 1984;37(910):755-764.

10. Levinson W, Roter DL, Mullooly JP, Dull VT, Frankel RM. Physicianpatient communication. The relationship with malpractice claims among primary care physicians and surgeons. JAMA. 1997;277(7): 553-559.

11. Ong LM, de Haes JC, Hoos AM, Lammes FB. Doctor-patient communication: a review of the literature. Soc Sci Med. 1995;40(7):903-918

12. Hall JA, Roter DL, Katz NR. Meta-analysis of correlates of provider behavior in medical encounters. Med Care. 1988;26(7):657-675.

13. Shaughnessy AF, Slawson DC, Becker L. Clinical jazz: harmonizing clinical experience and evidence-based medicine. J Fam Pract. 1998;47(6):425-428.

14. Roter DL, Stewart M, Putnam SM, et al. Communication patterns of primary care physicians. JAMA. 1997;277(4):350-356.

15. Committee on Quality of Health Care in America, Institute of Medicine. Crossing the Quality Chasm: A New Health System for the 21st Century. Washington, DC: National Academy Press; 2001.

16. Kleinman A. The Illness Narratives: Suffering, Healing and the Human Condition. New York, NY: Basic Books; 1988.

17. Nachmanovitch S. Free Play: Improvisation in Life and Art. New York, NY: Tarcher/Putnam; 1990.

18. Miller WL, McDaniel RR Jr, Crabtree BF, Stange KC. Practice jazz: understanding variation in family practices using complexity science. J Fam Pract. 2001;50(10):872-878.

19. Barrett FJ. Creativity and improvisation in jazz and organizations: implications for organizational learning. Org Sci. 1998;9:88-105.

20. Ward G, Burns K. Jazz: A History of America's Music. New York, NY: Knopf/Random House; 2000.

21. King J. What Jazz Is: An Insider's Guide to Understanding and Listening to Jazz. New York, NY: Walker; 1997.

22. Nisenson E. Round About Midnight: A Portrait of Miles Davis. New York, NY: Da Capo Press; 1996.

23. Roter D, Hall J. Doctors Talking With Patients/Patients Talking With Doctors. Westport, Conn: Auburn House; 1993.

24. Roter DL, Larson S, Shinitzky H, et al. Use of an innovative video feedback technique to enhance communication skills training. Med Educ. 2004;38(2):145-157.

25. Stiles WB, Putnam SM. Verbal exchanges in medical interviews: concepts and measurement. Soc Sci Med. 1992;35(3):347-355.

26. Inui TS, Carter WB, Kukull WA, Haigh VH. Outcome-based doctorpatient interaction analysis: I. Comparison of techniques. Med Care. 1982;20(6):535-549.

27. Del Piccolo L, Putnam SM, Mazzi MA, Zimmermann C. The biopsychosocial domains and the functions of the medical interview in primary care: construct validity of the Verona Medical Interview Classification System. Patient Educ Couns. 2004;53(1):47-56. 
28. Barr DA. A time to listen. Ann Intern Med. 2004;140(2):144.

29. Hentoff N. Untitled liner notes from the CD The Legendary OKEH and Epic Recordings by Ahmad Jamal: Epic/Legacy Recordings; 2005

30. Haidet P, Paterniti DA. "Building" a history rather than "taking" one: a perspective on information sharing during the medical interview. Arch Intern Med. 2003;163(10):1134-1140.

31. Frankel RM, Stein T. Getting the most out of the clinical encounter: the four habits model. J Med Pract Manage. 2001;16(4):184-191.

32. Kleinman AM. Interpreting illness meanings: the clinician's miniethnography. Med Encounter. 1986;3:5-7.

33. Marvel MK, Epstein RM, Flowers K, Beckman HB. Soliciting the patient's agenda: have we improved? JAMA. 1999;281(3):283-287.

34. Frankel RM, Beckman HB. The pause that refreshes. Hosp Pract (Off Ed). 1988;23(9A):62, 65-67.

35. Beckman $\mathrm{H}$, Frankel R. The impact of physician behavior on the collection of data. Ann Intern Med. 1984;101:692-696.

36. Ellison R. Living With Music: Ralph Ellison's Jazz Writings. New York, NY: The Modern Library; 2002.

37. Epstein RM. Mindful practice. JAMA. 1999;282(9):833-839.

38. Novack DH, Suchman AL, Clark W, Epstein RM, Najberg E, Kaplan C. Calibrating the physician. Personal awareness and effective patient care. Working Group on Promoting Physician Personal Awareness, American Academy on Physician and Patient. JAMA. 1997:278(6):502-509.

39. Nisenson E. Ascension: John Coltrane and His Quest. New York, NY: Da Capo Press; 1995

40. Smith R. The Patient's Story: Integrated Patient-Doctor Interviewing. Boston, Mass: Little Brown; 1996.

41. Coulehan J, Block M. The Medical Interview: Mastering Skills for Clinical Practice. 3rd ed. Philadelphia, Pa: FA Davis; 1997.

42. Quill TE, Townsend P. Bad news: delivery, dialogue, and dilemmas. Arch Intern Med. 1991:151(3):463-468.
43. Baile WF, Buckman R, Lenzi R, et al. SPIKES-A six-step protocol for delivering bad news: application to the patient with cancer. Oncologist. 2000;5(4):302-311.

44. Garg A, Buckman R, Kason Y. Teaching medical students how to break bad news. CMAJ. 1997;156(8):1159-1164.

45. Beach MC, Inui T. Relationship-centered care. A constructive reframing. J Gen Intern Med. 2006;21(Suppl 1):S3-S8.

46. Evans B. Improvisation in Jazz. Liner notes from the CD Kind of Blue by Miles Davis: Columbia/Legacy; 1997.

47. Pettinger P. Bill Evans: How My Heart Sings. New Haven, Conn: Yale University Press; 2002.

48. Street R. Accommodation in medical consultations. In: Giles H, Cou pland N, Coupland J, eds. Contexts of Accommodation: Developments in Applied Sociolinguistics. Cambridge, Mass: Cambridge University Press: 1991.

49. Platt FW, McMath JC. Clinical hypocompetence: the interview. Ann Intern Med. 1979;91(6):898-902.

50. Platt FW, Platt CM. Two collaborating artists produce a work of art: the medical interview. Arch Intern Med. 2003;163(10):1131-1132.

51. Kleinman A, Eisenberg L, Good B. Culture, illness, and care: clinical lessons from anthropologic and cross-cultural research. Ann Intern Med. 1978;88(2):251-258.

52. Heisler M, Vijan S, Anderson RM, et al. When do patients and thei physicians agree on diabetes treatment goals and strategies, and what difference does it make? J Gen Intern Med. 2003;18(11):893-902.

53. Levinson W, Gorawara-Bhat R, Lamb J. A study of patient clues and physician responses in primary care and surgical settings. JAMA. 2000;284(8):1021-1027.

54. Lang F, Floyd MR, Beine KL. Clues to patients' explanations and concerns about their illnesses. A call for active listening. Arch Fam Med. 2000;9(3):222-227.

55. Haidet P. Finding our way 'into the pocket' with patients. Med Encounter. 2005;19(2):34. 